\title{
Covid-19 and violence against women and children: time to mitigate the shadow pandemic
} Cite this as: BMJ 2021;375:n2903 http://dx.doi.org/10.1136/bmj.n2903 Published: 24 November 2021

\author{
Helga Fogstad, Etienne V Langlois, Teesta Dey
}

Covid-19 has highlighted the urgency of addressing violence against women and children, which reports suggest has increased during the pandemic. Often referred to as a "shadow pandemic," ${ }^{1}$ the rise in violence over the past two years has been linked to lockdowns and other restrictions on movement put in place due to covid-19, which force women and children to remain at home with their abusers.

Violence against women and girls was already a huge global problem before the pandemic. However, for many years it was largely invisible within national and international statistics and surveillance systems. Data from just before the pandemic showed that more than 640 million women worldwide aged 15 and older have been subjected to intimate partner violence at least once in their lifetime ( $26 \%$ of partnered women aged 15 and older). ${ }^{2}$ Twenty two per cent of partnered women living in the "least developed countries" had experienced it in the past 12 months-substantially higher than the world average of $13 \% .^{2}$

For a variety of reasons, the jump in violence against women and children during covid-19 may not show up in medical records. A reduction in face-to-face appointments with doctors and health workers, for example, and restricted access to hospitals during the pandemic will have limited opportunities to record physical evidence of abuse. However, the data from other sources are overwhelming.

Eighty per cent of recent studies on trends in violence against women and children found evidence of increased violence during the covid-19 pandemic. ${ }^{3}$ Domestic violence hotlines in some countries reported a fivefold increase in calls after physical distancing and lockdown measures were introduced. 4

Some common risk factors that increase the likelihood of perpetrators committing violence have ratcheted up during the pandemic-for example, cramped living conditions; limited mobility; and increased insecurity over health, jobs, and money. Outside the home, deserted public spaces made women and children even more vulnerable to assault and harassment.

The world needs to take urgent action to stem this upsurge in violence against women and children.

\section{Entrenched discrimination}

The pandemic has been an enabler of violence against women and children. However, it is just the latest facet of an outrage that refuses to go away, despite multiple attempts to address it. These efforts include making ending violence a key focus within sustainable development goal 5 . $^{5}$

Interpersonal violence has multiple, often interlinked, physical and mental health impacts for women and children. For example, unwanted pregnancies, adverse maternal and newborn health outcomes, sexually transmitted infections and HIV infection, and gynaecological problems may be among the harms women experience when it comes to their sexual and reproductive health. ${ }^{6}$

Most violence against women is perpetrated by current or former husbands or intimate partners. Intimate partner violence against women can often continue or start during pregnancy, leading to miscarriages, stillbirths, premature birth, and low birth weight babies. ${ }^{6}$

In some settings, gender inequality and discrimination against women are accepted and effectively sanctioned by society. Because of this, women and girls experience shame and stigma, and the violence often remains hidden.

The problem is usually most acute in low and middle income countries and other settings where women have limited access to quality, safe care and to high quality information about their rights and services. All too often, governments, health systems, and other institutions are slow to recognise and address violence, and services are not available or have limited capacity.

\section{Time to act}

As a first step, women need access to essential knowledge and support. PMNCH has taken a lead by producing a short animated film in partnership with the World Health Organization, UNICEF, and other UN partner agencies, which is the latest in the $\mathrm{PMNCH}$ series on self-care. ${ }^{7}$ It highlights in straightforward language the steps women can take to protect themselves and their children from violence in the home. These include creating a code word or signal to alert trusted friends and family members and having an escape plan if you need to move to a safe place.

Yet tackling the problem will need to go much further than this. In 2016, the World Health Organization published a global plan of action to address violence against women, children, and girls. ${ }^{6}$ It proposed a four-pronged approach: firstly, strengthen health system leadership and governance; secondly, strengthen health service delivery and health workers' capacity to respond; thirdly, strengthen programming to prevent interpersonal violence; and lastly, improve information and evidence. The global action plan takes a life course approach to preventing violence, aiming to increase the effectiveness of interventions targeted at both survivors and perpetrators throughout their lives. One example of this is the development of national prevention programmes that challenge harmful gender norms, such as those that perpetuate male dominance and 
female subordination, stigmatise survivors, and condone or normalise violence against women and children. Stronger financing, better policies, and better service delivery are also essential to drive change.

Five years on, these measures are needed more than ever-especially in the middle of a global pandemic that seems to have spurred abusers to commit more acts of violence. The needs of women, girls, and children experiencing violence cannot be put on pause and neither can the response.

Competing interests: none declared.

1 The shadow pandemic: violence against women during covid-19. UN Women. https://www.unwomen.org/en/news/in-focus/in-focus-gender-equality-in-covid-19-response/violence-againstwomen-during-covid-19

2 Violence Against Women Prevalence Estimates. 2018. World Health Organization. 9 March 2021. https://www.who.int/publications/i/item/9789240022256

3 Bourgault S, Peterman A, O'Donnell M. Violence against women and children during covid-19-one year on and 100 papers in: A fourth research round up. Center for Global Development. 12 April 2021. https://www.cgdev.org/publication/violence-against-women-and-children-during-covid19-one-year-and-100-papers-fourth

4 Intensification of efforts to eliminate all forms of violence against women: Report of the secretary-general (2020). UN Women. https://www.unwomen.org/en/digital-library/publications/2020/07/a-75-274-sg-report-ending-violence-against-women-and-girls

5 Envision2030 Goal 5: Gender Equality. United Nations. https://www.un.org/development/desa/disabilities/envision2030-goal5.html

6 Global plan of action to strengthen the role of the health system within a national multisectoral response to address interpersonal violence, in particular against women and girls, and against children. World Health Organization. 2016. http://apps.who.int/iris/bitstream/handle/10665/252276/9789241511537-eng.pdf;jsessionid=90C9BB1CEC79E4751BB7342781FAB7AC? sequence=1

7 Self-care during covid-19. Partnership for Maternal, Newborn and Child Health (PMNCH). https://pmnch.who.int/resources/multimedia/self-care-during-covid-19 